\title{
Analysis of Spin-Torque Noise in a CPP-GMR Head
}

\author{
T. Yoshino, *Y. Kanai, and K. Yoshida \\ Kogakuin University, 1-24-2 Nishishinjuku, Shinjuku-ku, Tokyo 163-8677, Japan \\ *Niigata Institute of Technology, 1719 Fujihashi, Kashiwazaki 945-1195, Japan
}

Technologies for realizing areal recording densities of over $1 \mathrm{Tbit} / \mathrm{inch}^{2}$ in hard disk drives have been aggressively developed. At such high densities, it is necessary that a read head should be able to sense a weak magnetic field straying from a recorded medium. One of the most promising candidates for such a head is a current-perpendicular-to-plane giant magnetoresistive (CPP-GMR) head. However, it has been pointed out that in a CPP-GMR head, injection of polarized spin into a free layer causes spin-torque noise, which is peculiar to CPP-GMR heads. Several experimental and theoretical results on spin-torque noise have been reported. Thus, it is necessary to investigate the relationships of spin-torque noise with various parameters of a CPP-GMR head. In this paper, the dependencies of the spin-torque noise power and spectrum on the amplitude of the sense current density, its polarity, and the amplitude of the exchange interaction acting on the pinned layer are investigated by means of micromagnetic simulation. As a result, it is clarified that the noise properties are strongly influenced by the polarity of the injected spin, and that the noise power spectrum is located in narrow regions of frequency space.

Key words: micromagnetic simulation, current-perpendicular-to-plane giant magnetoresistive head, spin-torque noise

\section{CPP-GMR ヘッドにおけるスピントルクノイズの解析}

吉野剛史・金井靖*・吉田和悦

工学院大学, 東京都新宿区西新宿 1-24-2 (广163-8677)

*新潟工科大学, 新潟県柏崎市藤橋 1719 ( ( $945-1195)$

\section{1.はじめに}

現在，磁気ディスク装置 (HDD) において, 1 Tbit/inch ${ }^{2}$ 以上の 高面記録密度の実現に向けて研究が進められている. 高記録密度 実現時には, それに対応した再生ヘッドが求められる. そのため, これまで用いられてきた巨大磁気抵抗効果(GMR)再生ヘッドに代 わる，新たな再生ヘッドが必要となる，そのためには，再生へッ ドの小型化, 再生信号の出力増大, 再生時に発生するノイズの抑 制が求められる. これらの条件を満たす再生ヘッドとして垂直通 電型巨大磁気抵抗効果(CPP-GMR)再生ヘッドが有望視されている。

CPP-GMR ヘッドは, 従来の再生ヘッドと比較して高い磁気抵抗 変化率(MR 比)を実現可能であり，これまでにヘッドノイズとして 知られていたジョンソンノイズやショットノイズを低減すること ができる ${ }^{1)}$. しかしその一方で, センス電流密度が大きくなると, 固定層から自由層へ注入された電子によって起こるスピントルク ノイズが無視できない程に増大し, 実用化上の問題となっている 事が指摘されている2).

このスピントルクノイズについては, 既にヘッド素子の形状や 固定層・自由層の 2 層間でのスピン角度差が, ノイズのパワーに 変化を与えることが報告されている3)。この事から, CPP-GMR ヘッドにおいてスピントルクノイズに影響を与える因子について, 詳しく調べることが重要である.

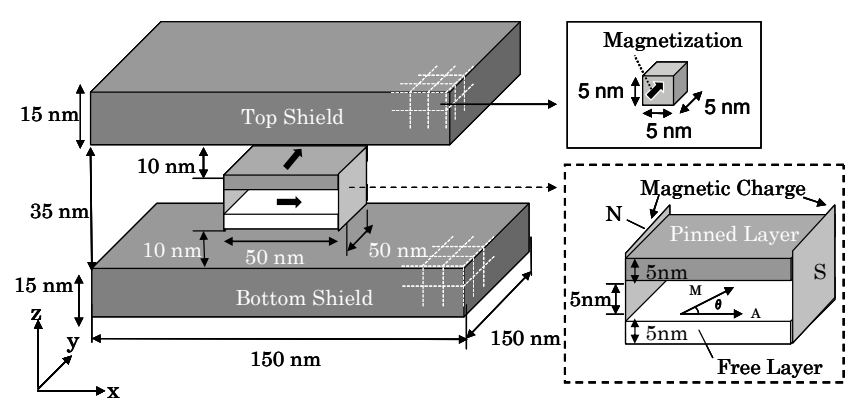

Fig. 1 CPP-GMR head calculation model.
本論文では, CPP-GMRヘッド素子の中からセンス電流密度及び 流入方向, 素子の固定層に掛かる交換磁界の 3 つを可変パラメー タとして選び，それらが変化した時のスピントルクノイズに現れ る影響を，マイクロマグネティック解析シミュレーションを用い て検討した.

\section{2. 計算モデル}

Fig. 1 に今回の計算で用いたCPP-GMR 再生ヘッドシミュレータ の計算モデルを示す．計算領域としては，磁化のベクトル方向を 単一方向に固定した固定層, 外部からの磁界によって, 磁化の ベクトル方向が変化する自由層の 2 層からなる CPP-GMR 素子を, 上下のシールドで挟んだ構造をもつ. この計算領域は全て 1 辺が $5 \mathrm{~nm}$ の立方体セルによって離散化されており, 各セルがそれぞれ 磁化ベクトルを持つものとして計算を行った．なお，実際の CPP-GMR 素子においては固定層の磁化を固定する為の反強磁性 層が存在するが，今回の計算では計算過程の簡略化のために省略 した. その代わり, 固定層の素子高さ方向 $\left(\mathrm{y}\right.$-軸)に交換磁界 $\mathbf{H}_{\mathrm{v}}$ を 印加し, 反強磁性層の役割とした. 磁化挙動は, Landau-LifshitzGilbert (LLG)方程式を用いて計算機シミュレーションにて求めた. 自由層の磁化については偏極スピンによるスピントルクを考慮す る必要があるため, 式(1)に示す様に従来の LLG 方程式にスピント ルク項を追加して計算を行った ${ }^{4), 5), 6) . ~}$

$$
\begin{gathered}
\left(1+\alpha^{2}\right) \frac{d \mathbf{M}}{d t}=-\lambda \mathbf{M} \times\left(\mathbf{H}_{\text {teff }}-\alpha \mathbf{H}_{s t}\right)-\frac{\lambda}{M_{s}} \mathbf{M} \times \mathbf{M} \times\left(\alpha \mathbf{H}_{\text {teff }}+\mathbf{H}_{s t}\right) \\
\mathbf{H}_{s t}=\mathrm{a}_{\mathrm{j}} \mathbf{m}_{p}=\frac{\hbar \eta J \mathbf{m}_{p}}{2 e M_{s} d}
\end{gathered}
$$

ここで， $\mathbf{H}_{\mathbf{s t}}$ は偏極スピンによるスピントルクの磁界ベクトル， $\mathrm{a}_{\mathrm{j}}$ はスピントルク磁界の大ささ, $\mathrm{J}$ は電流密度, $\eta$ はスピン分極率 を表す．また， $\mathrm{m}_{\mathrm{p}}$ は電子の極性を示す偏極スピンの単位ベクトル である. 電流の向きについては, Fig. 2 の様に自由層から固定層に 
流れる時，即ち電子が固定層から自由層へと流れる方向を正，逆 方向を負と定義した. これについては後ほど 4 章の冒頭で述べる.

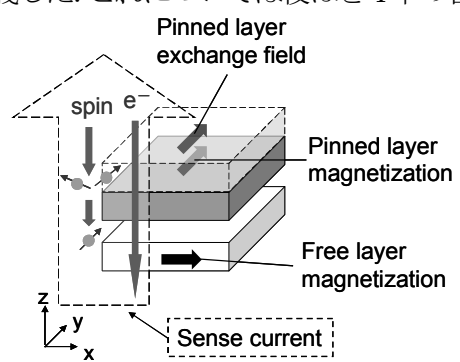

Fig. 2 Sense current and magnetizations in CPP-GMR head.

\section{3. 計算条件}

今回の計算では固定層及び自由層を厚さ $5 \mathrm{~nm}$, 面積 $50 \times 50 \mathrm{~nm}^{2}$ の正方形とし, 各層の磁化容易軸方向を固定層では $+\mathrm{y}$ 方向, 自由 層では $+\mathrm{x}$ 方向に設定し, 各層の初期磁化方向は各層の磁化容易方 向に設定した. 自由層においては，磁化方向を $\mathrm{x}$ 軸方向に向ける ため, Fig. 1 の破線内に示したように層の両端に $0.5 \mathrm{~T}$ の表面磁荷 を置き，そこから発生する磁界をもって縦バイアスとした．計算 の時間刻み幅 $(\Delta \mathrm{T})$ は $0.1 \mathrm{ps}$ ，反復計算は 10 万回とし，10 ns の時間 間隔における磁化挙動を計算した.

その他，今回の計算で設定したパラメータをTable 1 に示寸. 本計算では, センス電流の密度, 素子の固定層に加わる交換磁界, センス電流の流入方向の順でそれぞれのパラメータを変化させた 時の自由層の抵抗值を計算した. この時に発生する抵抗值の摇ら ぎをノイズと定め, その変動を計算すると共に, 導出した結果に フーリエ変換を行ってノイズパワースペクトラム（以下，ノイズ パワー）を求め, CPP-GMR素子におけるスピントルクノイズの 影響について検討した.

Table 1 Magnetic properties of CPP-GMR head.

\begin{tabular}{|c|c|}
\hline Parameters & Value \\
\hline $\begin{array}{c}\mathrm{a}_{\mathrm{j}}[\mathrm{A} / \mathrm{m}] \\
\left(\text { Sense current } \mathrm{I}_{\mathrm{j}}\left[\mathrm{A} / \mathrm{m}^{2}\right]\right)\end{array}$ & $\begin{array}{c}-6.0 \sim 6.0 \times 10^{4} \\
\left(-3.65 \sim 3.65 \times 10^{12}\right)\end{array}$ \\
\hline Pinned layer exchange field $\mathrm{H}_{\mathrm{v}}[\mathrm{A} / \mathrm{m}]$ & $4.0 \times 10^{4} \sim 1.6 \times 10^{5}$ \\
\hline Anisotropy constant $\mathrm{K}\left[\mathrm{J} / \mathrm{m}^{3}\right]$ & $5.0 \times 10^{3}$ \\
\hline Stiffness constant A $[\mathrm{J} / \mathrm{m}]$ & $1.0 \times 10^{-11}$ \\
\hline Surface charge Schg $[\mathrm{T}]$ & 0.5 \\
\hline Spin polarization factor $\eta$ & 0.5 \\
\hline Time discretization $\Delta \mathrm{T}[\mathrm{sec}]$. & $1.0 \times 10^{-13}$ \\
\hline Saturation magnetization Ms $[\mathrm{T}]$ & 1.0 \\
\hline
\end{tabular}

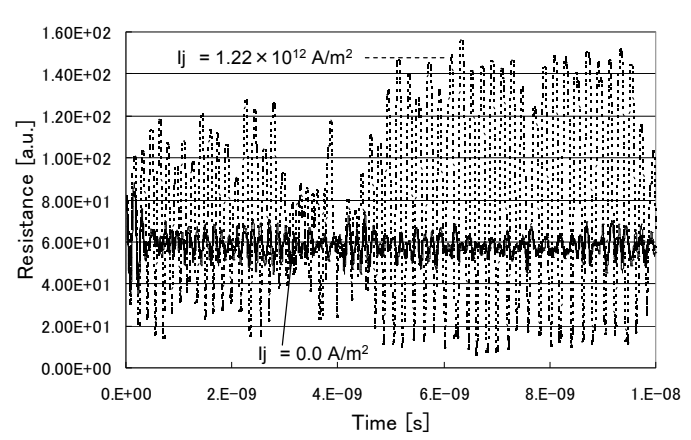

Fig.3 Resistance change of free layer in time-space for $\mathrm{Ij}=0.0$ and $1.22 \times 10^{12} \mathrm{~A} / \mathrm{m}^{2}$.

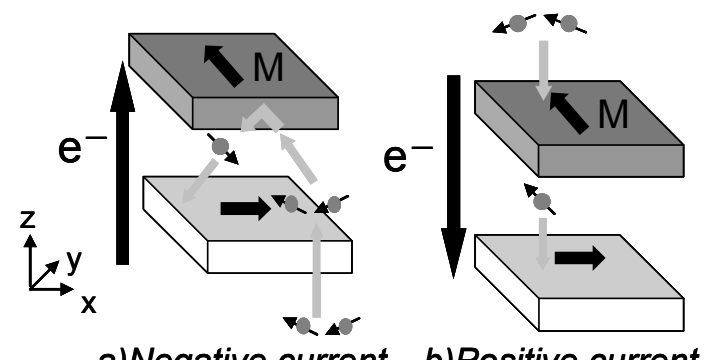

a)Negative current b)Positive current

Fig. 4 Sense current and magnetization in CPP-GMR head.

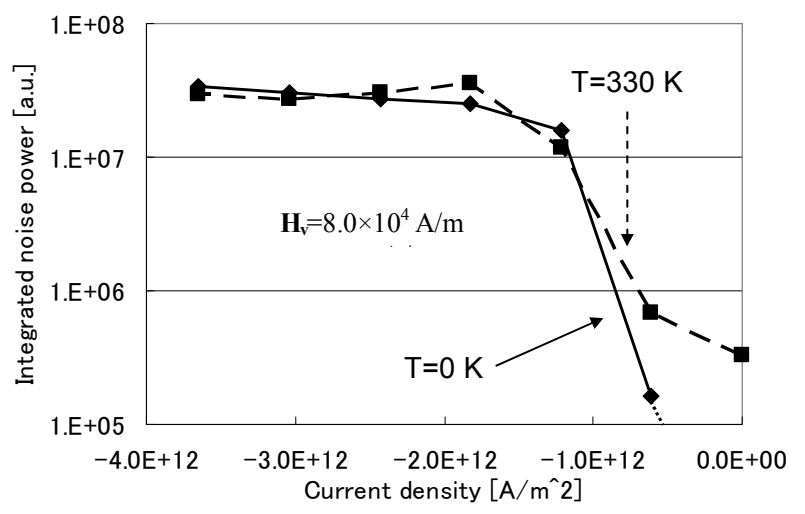

Fig.5 Temperature dependence of noise power on current density.

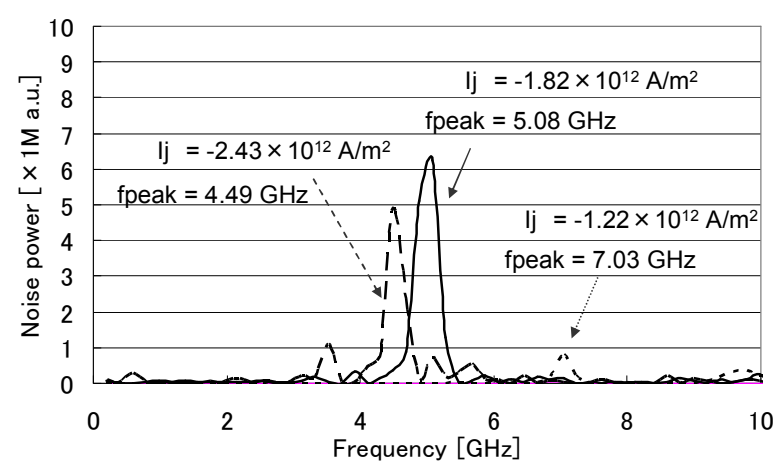

Fig.6 Noise power spectrum for various current density.

\section{4. 計算結果}

Fig. 3 に実時間における抵抗值の摇らぎ波形の例を示寸.この グラフは全計算結果から $5 \mathrm{ps}$ 毎に抵抗值をサンプリングし, 合計 2000 点プロットしたものである. 計算開始後しばらくは磁化の初 期状態から安定状態に至るまでの緩和過程である。このことから, ノイズパワーを得るためのフーリエ変換は前半部を避け, 後半の 1024 点(5.0〜 $10.0 \mathrm{~ns}$ 区間)を対象としてサンプリングした.

この時, 次節の 4.1 及び 4.2 で計算する結果は, いずれも CPP-GMR 素子に対して負方向の電流を流した状態を前提として 求めている. この時電子は自由層から固定層に向かい, 固定層に おいて反射した一部の電子が，固定層磁化と反平行のスピンをも って自由層に注入される(Fig. 4a). 従って, 固定層磁化と反平行な スピンが自由層に注入された場合についてノイズパワーが算出さ れる. 一方, 4.3 で求める正方向の電流注入時には, 電子が固定層 から自由層に流入する際, 固定層磁化のスピンと平行のスピンの みが通過してくる(Fig. 4b)ために, 結果として自由層に平行のスピ ンが作用する場合について検討した. 


\section{1 温度 - 電流密度依存性}

Fig. 5 に，負方向の電流を流した場合の温度 $\mathrm{T}=0$ および $330 \mathrm{~K}$ における積分ノイズパワーのセンス電流依存性を示寸.ここで, 積分ノイズパワーとは今回計算した $0 \sim 10 \mathrm{GHz}$ 帯域におけるノイ ズパワーの積分值と定義した. この時の固定層交換磁界強度 $\mathrm{H}_{\mathrm{v}}$ は $8.0 \times 10^{4} \mathrm{~A} / \mathrm{m}$ である. 電流密度が低い場合は $330 \mathrm{~K}$ の時のみノイ ズが発生しているが, いずれも電流密度の絶対值が $0.6 \times 10^{12} \mathrm{~A} / \mathrm{m}^{2}$ を超えると積分ノイズパワーが 1 桁以上増大し，その後は更に電 流密度を上げても変化が起きず，ほぼ飽和状態となる事が分かっ た.この事から電流密度にはノイズ増大が始まる閾值が存在する 事が分かった.

次に， $\mathrm{T}=330 \mathrm{~K}$ で電流密度を変化させた時のノイズパワーを Fig.6 に示寸. 図では電流密度が䦨值を越えて, 積分ノイズパワー が急増する $-1.22 \times 10^{12} \mathrm{~A} / \mathrm{m}^{2}$ 以上におけるノイズパワーのみを示 した．図から分かるように，ノイズのスペクトラムには，はっき りしたピークが現われており，ノイズパワーは特定の周波数に集 中していることが分かる，そのピーク位置は電流密度の増大によ り低周波側一と遷移していく. 一方，Fig. 5 に示したように，1.22 $\times 10^{12} \mathrm{~A} / \mathrm{m}^{2}$ 以降では積分ノイズパワーがほとんど変化していない ことから，ピーク值が減少する場合は，ノイズがピーク位置の周 波数以外の領域に拡散することが分かる. また, $\mathrm{Ij}=1.82 \times 10^{12} \mathrm{~A} / \mathrm{m}^{2}$ の場合では, $5 \mathrm{GHz}$ に明膫なピークが現われており，これが電流密 度を変化させた中で最も大きなピークだった。

\section{2 固定層交換磁界強度依存性}

Fig.7 に， $\mathrm{T}=330 \mathrm{~K}$ における固定層交換磁界強度 $\mathrm{H}_{\mathrm{v}}$ の值による 積分ノイズパワーの変化を示寸. グラフに示寸ように, 電流密度 が小さい場合では, 固定層交換磁界強度が強いほど積分ノイズパ

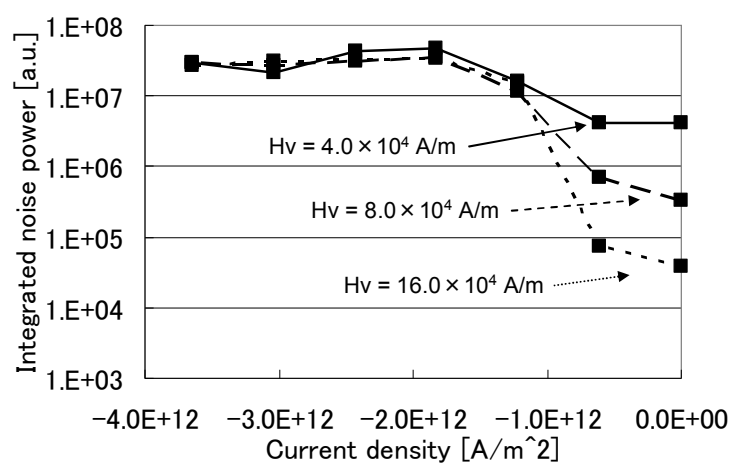

Fig. 7 Pinned layer exchange field dependence of noise power on current density.

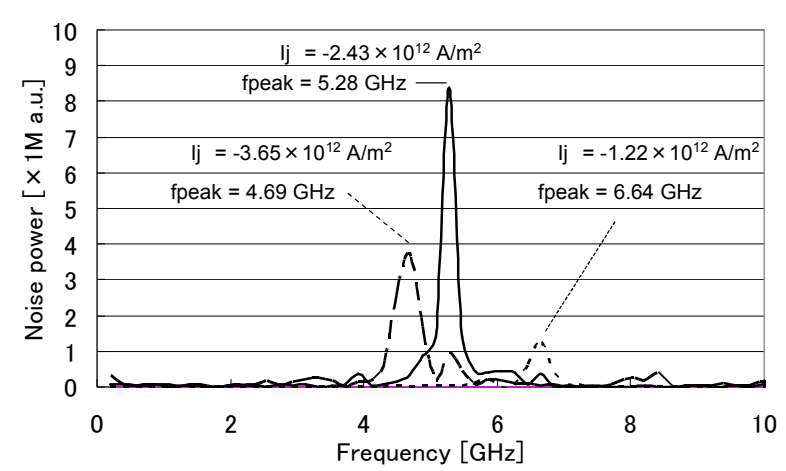

Fig. 8 Noise power spectrum for $\mathrm{H}_{\mathrm{v}}=1.6 \times 10^{5} \mathrm{~A} / \mathrm{m}$.

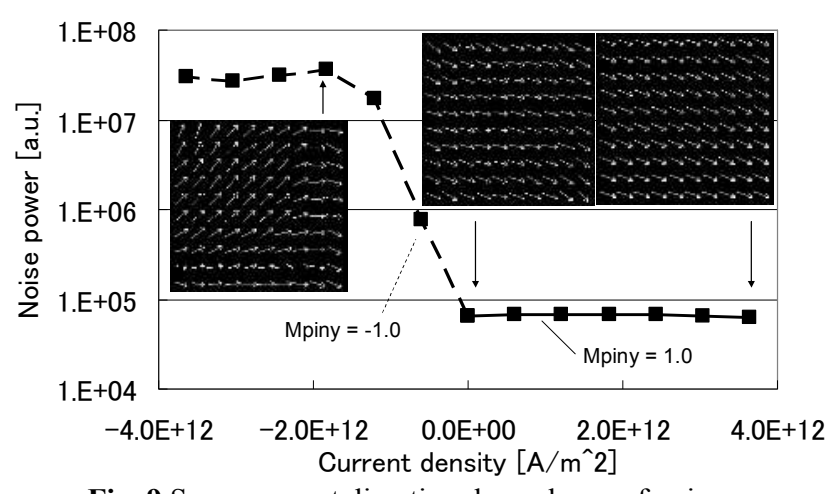

Fig. 9 Sense current direction dependence of noise power.

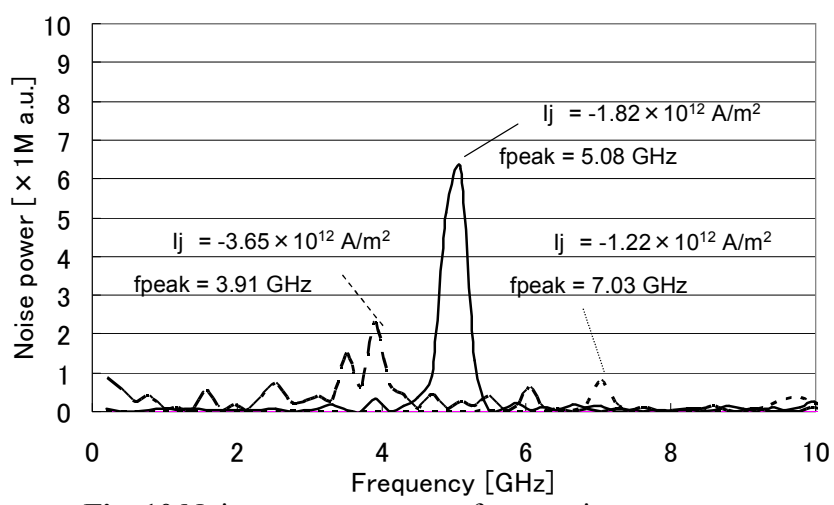

Fig. 10 Noise power spectrum for negative sense current.

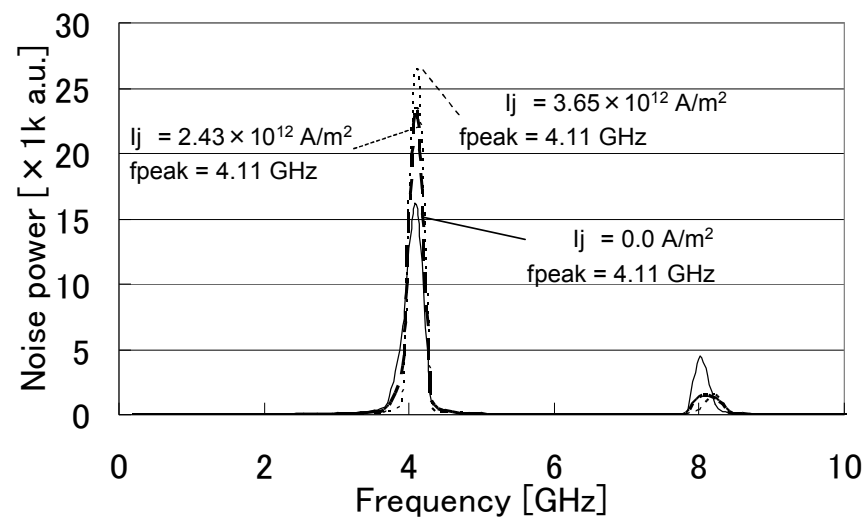

Fig. 11 Noise power spectrum for positive sense current.

ワーが小さく抑えられる事がわかる。このことから，低電流密度 の条件下であれば，固定層交換磁界強度を増大させることにより 積分ノイズパワーを抑える事ができるという結果を得た。

次に, 固定層交換磁界強度 $\mathrm{H}_{\mathrm{v}}$ を $1.6 \times 10^{5} \mathrm{~A} / \mathrm{m}$ と強くした時の ノイズパワーを Fig. 8 に示す. $\mathrm{H}_{\mathrm{v}}=8.0 \times 10^{4} \mathrm{~A} / \mathrm{m}$ で計算を行った Fig.6 と比較すると, 同じ電流密度で計測を行った時のノイズピー クの值が増大しピークの裙野が狭くなってより鋭くなっている事 が分かった. 固定層交換磁界蚛度の増大により, 固定層を通過し てくるスピンの方向がより強く揃えられ，ノイズ源となる磁化の 振動が特定周波数一と集中したためにノイズパワーの集中が進み, 波形がより急峻になったと考えられる.

\section{3 センス電流方向依存性}

Fig. 9 に, 固定層磁化と平行なスピンを注入した場合の, 積分 ノイズパワーおよび自由層磁化分布の状態変化を示す. 図では, 
反平行なスピンを注入した場合と比較するため, Fig.5 で求めた積 分ノイズパワーも併せて破線で示した. その結果, 実線で示され た平行スピン時ではノイズが低い状態のまま増大せず，計算した 值の範囲内では目立った閾值が見られなかった.

その原因を調べるため，これらの時の自由層の磁化分布を調心゙ た. まず, $\mathrm{Ij}=0.0 \mathrm{~A} / \mathrm{m}^{2}$ の時は磁化に細かなばらつきが見られるが, 全体的に右下に向いている. これは固定層から自由層にかかる磁 界が -y 方向を向いているためである. スピンを注入した場合では, 反平行では磁化方向が著しく乱れてノイズの発生が明確であるの に対し, 平行では磁化方向が揃っており, $\mathrm{Ij}=0.0$ の時と大きな違い は見られなかった。

また，負方向電流によるノイズパワースペクトラム(Fig. 10) お よび正方向電流によるノイズパワースペクトラム(Fig. 11)を比べ ると, 正方向電流ではスペクトラムのピーク周波数ノイズがおよ そ 2 桁程度小さかった他, 負方向電流を流した時に生じたピーク 周波数の遷移やスペクトル拡散が正方向電流で現れない事が分か った.

これらの結果から, CPP-GMRヘッドに注入する電流の方向に よって, スピントルクノイズの積分ノイズパワー, およびピーク 周波数の遷移に著しい変化が現れる事がわかる.

なお，このようにノイズパワーに電流方向依存性が現れるのは, 計算モデルにおいて固定層を単層と仮定したためであり，今現在 用いられている，固定層を互いに反平行磁化状態にある 2 層で構 成する場合ではまた異なった傾向が見られると推測される.

\section{5. まとめ}

マイクロマグネティックシミュレータを用いて, CPP-GMR 再生 ヘッドに発生するスピントルクノイズについて計算を行った. 温 度, 電流密度, 固定層交換磁界強度の各值, およびセンス電流方 向を変化させた時の積分ノイズパワー，およびノイズパワースペ クトラムへの影響について検討し以下の結果を得た。

1) 負方向の電流を流して固定層磁化方向と反平行のスピンを 注入した場合, センス電流の密度がある一定の閾值を超え ると積分ノイズパワーが著しく増大し，それ以上の電流密 度では次第に飽和するようになる.

2) 正方向の電流により固定層磁化と平行方向のスピンを注入 した場合には、反平行のスピンを注入した場合と比較して 積分ノイズパワーが著しく減少すると共に，ノイズパワー が増大する閾值も見られなかった。

3) 積分ノイズパワーが未飽和の電流領域では，固定層交換磁 界強度が強いほど積分ノイズパワーが抑えられるが，積分 ノイズパワーが飽和した状態では固定層交換磁界強度依存 性は見られなかった。

\section{References}

1) M.Shiimoto, H.Katada, K.Nakamoto, H.Hoshiya, M.Hatatani, A.Namba, J.Magn.Soc.Jpn.,Vol.31, pp.54-57(2007).

2) Jian-Gang Zhu, Xiaochun Zhu, IEEE Trans. Magn. Vol. 40, pp. 182 -188(2004).

3) 椎本正人, 片田裕之, 中本一広, 星屋裕之, 池田悠太, 星野勝 美, 芳田伸雄, J. Magn. Soc. Jpn., Vol.32, No.2-1, pp.54-57 (2008).

4) Z. Li and S. Zhang, "Magnetization dynamics with a spin-transfer torque," Phys. Rev. B, Vol. 68, pp024404 (2003).

5) K.Yoshida, E.Uda, N.Udagawa, Y.Kanai, IEEE Trans. MAG. Vol. 44, No.11, pp.3408-3411(2008).

6) 宇田英世，横江真人，吉田和悦，金井靖, J.Magn.Soc.Jpn.,Vol.33, No. 4 pp.357-361 (2009).

2009 年 10 月 20 日受理, 2010 年 2 月 24 日採録 